\title{
Pengkajian Nyeri pada Pasien Kritis dengan Menggunakan Critical Pain Observation Tool (CPOT) di Intensive Care Unit (ICU)
}

\author{
Ayu Prawesti Priambodo, Kusman Ibrahim, Nursiswati \\ Fakultas Keperawatan Universitas Padjadjaran \\ Email :ayu.prawesti@unpad.ac.id
}

\begin{abstract}
Abstrak
Penggunaan alat ukur pengkajian nyeri yang sistematik dan terstandar pada pasien kritis yang tidak mampu untuk melaporkan rasa nyeri adalah suatu hal yang perlu diperhatikan. Behavioural pain scales (BPS) adalah alat ukur yang lebih dini dan banyak digunakan di area keperawatan kritis. Critical pain observation tools (CPOT) adalah alat yang dikembangkan menggunakan unsur-unsur rasa nyeri yang ada pada beberapa alat ukur pengkajian nyeri, termasuk BPS, namun CPOT belum banyak dikenal dan digunakan. Tujuan penelitian adalah melihat kesesuaian alat ukur CPOT dengan alat ukur BPS. Penelitian ini bersifat observasional analitik dengan rancangan Crosssectional dengan sampel pasien GICU (General Intensive Care Unit) dengan penurunan kesadaran dan menggunakan ventilasi mekanik sebanyak 48 pasien. Teknik pengambilan sampel dengan consecutive sampling. Pengkajian dilakukan dengan observasi skala nyeri menggunakan BPS dan CPOT pada saat pasien kondisi istirahat dan positioning untuk melihat keandalan alat ukur nyeri. Hasil uji beda dan korelasi pada hasil pengukuran nyeri pada BPS dan CPOT adalah bermakna. Hal ini menunjukkan bahwa BPS dan CPOT dapat mengukur perbedaan intensitas nyeri saat istirahat dengan saat positioning. Hasil uji kesesuaian (kappa) pengukuran BPS dengan CPOT memiliki nilai kesesuaian yang bermakna, dengan nilai kesesuaian (kappa) BPS-CPOT pada kondisi istirahat sebesar 0,937, sedangkan nilai kesesuaian (Kappa)BPS-CPOT pada kondisi positioning sebesar 0,265. BPS dan CPOT adalah alat penilaian nyeri yang dapat digunakan dalam menilai rasa sakit dan meningkatkan manajemen nyeri pada pasien kritis. CPOT lebih mudah digunakan dan aplikatif karena memiliki definisi operasional yang jelas.
\end{abstract}

Kata kunci : Behavioural pain scale, Critical pain observation tool, pasien kritis.

\section{Pain Assessment among Critically III Patients using the Critical Pain Observation Tool (CPOT) in the Intensive Care Unit}

\begin{abstract}
A systematic and standardised tool to assess pain experienced by critically ill patients has been previously highlighted. The BPS is the common tool used in the intensive care setting which can be used. But, the Critical Pain Observation Tool (COPT) has not been used extensively in the hospital. Thus, the efficacy of this tool needs to be examined. This descriptive observational study aimed to find an agreement of CPOT with BPS using a crosssectional method recruited 48 participants with consecutive sampling technique. Pain assessment was performed during a resting and positioning period to check the agreement of the tools. Data was analysed using Cohen's Kappa index analysis. Findings demonstrated a significance difference of pain intensity measured by BPS and CPOT during the period of resting $(\kappa=0.937)$ and positioning $(\kappa=0.265)$. Thus, BPS and CPOT are reliable scales to measure pain intensity. It is expected that those tools can help nurses to improve pain management for critically ill patients. However, CPOT is considered more applicable and user-friendly compared to the BPS.
\end{abstract}

Keywords: Behavioral Pain Scale, Critical Pain Observation Tool, critical nursing care. 
Ayu Prawesti Priambodo: Pengkajian Nyeri Pasien Kritis Menggunakan Critical Pain Observation Tool

\section{Pendahuluan}

Pasien di unit perawatan intensive memiliki berbagai pengalaman yang kompleks dan kondisi yang mengancam jiwa, dan memiliki masalah dengan rasa nyeri dan ketidaknyamanan (Gelinas, 2007). Insidensi nyeri pada pasien kritis lebih besar dari $50 \%$, pengalaman nyeri dirasakan ketika istirahat maupun selama menjalani prosedur klinis yang rutin dilaksanakan (Chanques et al., 2006, Payen et al., 2007, Puntillo et al., 2014). Sumber nyeri yang telah diidentifikasi adalah traumatik injuri, standar prosedur (pengangkatan drain/tube, mobilisasi, suction endotrakeal), penyakit akut, pembedahan, peralatan invasif (Siffleet et al., 2007, Puntillo et al., 2014). Tidak adekuatnya pengkajian nyeri dapat menyebabkan tidak dikenalinya masalah nyeri sehingga nyeri tidak tertangani. Nyeri yang tidak ditangani secara optimal dapat menimbulkan dampak yang buruk terhadap fungsi fisiologis (fluktuasi tandatanda vital, nosokomial infeksi), meningkatkan waktu rawat inap di ICU, meningkatkan waktu penggunaan ventilator (Canques et al., 2006, De Jong et al., 2013, Sessler et al., 2008, Payen et al., 2009, Futier et al., 2012). Selain hal tersebut, nyeri yang tidak tertangani juga bisa menyebabkan peningkatan tekanan intra kranial (Bor Seng et al., 2013), pada level yang tinggi juga memiliki konsekuensi menimbukan post traumatic stres disorder (Myhren et al.,2010)

Manajemen yang tepat dari nyeri tergantung pada pengkajian nyeri yang sistematis dan akurat (Herr et al., 2006). Nyeri seharusnya dikaji secara rutin dan terstruktur, tetapi hal ini seringkali tidak dilakukan (Barr et al., 2013). Alat ukur pengkajian nyeri yang valid dan direkomendasikan telah tersedia, namun banyak perawat yang tidak menggunakannya (Rose et al., 2012). Banyak pasien di ICU yang karena kondisi penyakitnya, menyebabkan pasien tidak sadarkan diri atau menggunakan alat bantu napas ventlator, sehingga mereka tidak dapat mengkomunikasikan rasa nyerinya. Hal ini menjadi suatu tantangan bagi perawat ICU, kerena beratnya intensitas nyeri pasien sering diremehkan (Ahlers et al., 2008). Hal ini disebabkan karena terdapat kelompok pasien ICU yang tidak dapat berkomunikasi secara efektif, sedangkan metoda self- report masih merupakan 'standar emas' dalam pengkajian nyeri sesuai dengan pedoman dari International Association for The Study of Pain. Di area keperawatan kritis banyak pasien dengan sedasi dan intubasi yang tidak mampu berkomunikasi untuk menunjukkan tingkat rasa nyeri mereka, baik secara lisan atau dengan menunjukkan tingkat rasa nyeri mereka dengan menggunakan alat bantu skala nyeri, hal ini membuat pegkajian nyeri sulit dilakukan dalam kelompok pasien ini (Pasero, 2009). Hal ini yang menyebabkan pengkajian nyeri di area keperawatan kritis merupakan hal yang sangat kompleks..

Kompleksnya pengkajian nyeri di area keperawatan kritis memerlukan pengkajian nyeri yang komprehensif sebagai evaluasi yang objektif melalui pengamatan pada indikator rasa nyeri. Namun, tidak ada alat yang sempurna untuk mengevaluasi rasa nyeri. Penggunaan skala nyeri berdasarkan indikator perilaku direkomendasikan untuk pasien yang tidak bisa mengkomunikasikan rasa nyerinya, dengan mengamati fungsi motorisnya (Barr et al., 2013)

Puntillo et al. (2014) meneliti perilaku yang ditunjukkan oleh pasien yang mengalami rasa nyeri dan mengidentifikasi sejumlah indikator perilaku nyeri (pada pasien yang sadar) dengan tujuan untuk dijadikan acuan dalam mengidentifikasi rasa nyeri pada pasien dengan sedasi dan tidak sadarkan diri. Termasuk meringis, kekakuan, menutup mata, dan mengepalkan tangan.

Berbagai alat ukur nyeri telah tersedia, tetapi belum secara pasti keandalannya untuk diterapkan dalam beragam populasi pasien ICU. Tahka et al (2009) mengidentifikasi lima alat ukur pengkajian nyeri untuk digunakan pada pasien kritis yang tidak mampu memverbalisasikan intensitas nyerinya,yaitu Behavioral Pain Scales (BPS), Critical Care Pain Observation Tool (CPOT), Non Verbal Adult Pain Assessment Scale (NVPS), Pain Assessment and Intervention Notation Algorithm (PAIN), dan Pain Assessment Algorithm.

Berdasarkan studi Tahka et al. (2009) disimpulkan bahwa diantara 5 alat ukur nyeri yang dikaji, BPS, CPOT dan NVPS memiliki nilai terbaik dalam quality assessment. Alat ukur BPS dan CPOT dinilai memiliki banyak kesamaan, yaitu alat ukur dengan satu 
Ayu Prawesti Priambodo: Pengkajian Nyeri Pasien Kritis Menggunakan Critical Pain Observation Tool

dimensi dan telah banyak diuji di area tatanan keperawatan kritis. Pada BPS dan CPOT seluruh evaluasi nyeri didasarkan pada tandatanda perilaku (behaviour). Fokus BPS dan CPOT adalah pada perubahan yang dihasilkan dari peningkatan intensitas nyeri di kedua parameter. Berbeda dengan CPOT dan BPS, NVPS menggunakan gerakan tubuh dengan cara yang mirip dengan BPS dan CPOT, tetapi untuk ekspresi wajah penilaiannya bergantung pada durasi ekspresi yang menunjukkan rasa nyeri selama periode pengukuran. Pada BPS dan CPOT seluruh evaluasi nyeri didasarkan pada tanda-tanda perilaku (behaviour). BPS ditemukan lebih dini dan lebih banyak digunakan daripada CPOT, namun CPOT memiliki indikator yang lebih komprehensif dan memiliki definisi operasional yang lebih detil. Oleh sebab itu penelitian ini bertujuan melihat kesesuaian CPOT dengan BPS. Penelitian ini bertujuan untuk mendapatkan alat ukur pengkajian yang tepat dan terbaik untuk meningkatkan kualitas perawatan untuk pasien dengan sakit kritis.

\section{Metode Penelitian}

Penelitian ini merupakan observasional analitik dengan rancangan cross sectional. Sampel penelitian adalah 48 pasien kritis dengan penurunan kesadaran dan ventilasi mekanis yang menjalani perawatan di ruang General Intensive Care Unit (GICU) di Rumah Sakit Hasan Sadikin Bandung. Penelitian menggunakan Consecutive sampling, dengan kriteria sampel berusia $\geq 18$ tahun, tidak dapat melaporkan rasa nyerinya, menggunakan ventilasi mekanik, pasien dengan tingkat kesadaran somnolens dan stupor, memiliki hemodinamik stabil.

Pasien dilakukan pengkajian nyeri pada saat pasien istirahat dan pada saat prosedur yang menyakitkan (nociceptive) yaitu perubahan posisi (repositioning). Pengkajian nyeri dilakukan menggunakan BPS yang berdasarkan pada tiga domain : ekspresi wajah, gerakan ekstremitas atas, dan kepatuhan dengan ventilasi mekanik (compliance ventilated). Pada pasien yang sama kemudian dilakukan pengkajian nyeri dengan CPOT yang berdasarkan pada empat domain: ekspresi wajah, gerakan tubuh, ketegangan otot, dan kepatuhan dengan ventilasi mekanis untuk pasien dengan intubasi dan vokalisasi untuk pasien ekstubasi. Pasien dinilai 0,1 , atau 2 pada empat domainnya, CPOT memberikan nilai keseluruhan dari 0 (tidak ada rasa sakit) sampai 8 (sakit maksimum) (Gelinas, Fillion, et al, 2006).

Pengujian nilai kesesuaian antara alat ukur CPOT dengan BPS, melalui beberapa tahap yaitu:

1. Uji beda rerata respon skor nyeri saat istirahat dan saat mobilisasi pada dua alat ukur Behavioural Pain Scales (BPS) dan Critical Pain Observation Tools (CPOT).

2. Uji hubungan dari dua alat ukur, Behavioural Pain Scales (BPS) dan Critical Pain Observation Tools (CPOT) dalam mengkaji nyeri pada pasien kritis dengan penurunan tingkat kesadaran (unconscious) dan ventilasi mekanik.

3. Uji kesesuaian (agreement) alat ukur Behavioural Pain Scales (BPS) dengan Critical Pain Observation Tools (CPOT) dengan kappa.

Tabel 1 Analisis Perbedaan Pengukuran Respon Nyeri Antara Kondisi Istirahat dan Positioning pada Alat Ukur BPS dan CPOT

\begin{tabular}{ccccc}
\hline & $\begin{array}{c}\text { Istirahat } \\
\left(\mathbf{M}_{\mathbf{e}} \text { (rentang) }\right.\end{array}$ & $\begin{array}{c}\text { Positioning } \\
\left(\mathbf{M}_{\mathbf{e}} \text { (rentang) }\right.\end{array}$ & $\mathbf{Z}$ & $\mathbf{p}$ \\
\hline Alat Ukur & 3 & 6 & $-6,069$ & $0,00^{*}$ \\
BPS & $(3-5)$ & $(4-10)$ & & $0,00^{*}$ \\
CPOT & 0 & 4 & -6.063 & \\
\hline Keterangan : ${ }^{*}$-value $<0,001$ & $(0-3)$ & $(1-6)$ & &
\end{tabular}

Keterangan : *p-value $<0,001$ 
Ayu Prawesti Priambodo: Pengkajian Nyeri Pasien Kritis Menggunakan Critical Pain Observation Tool

\section{Hasil Penelitian}

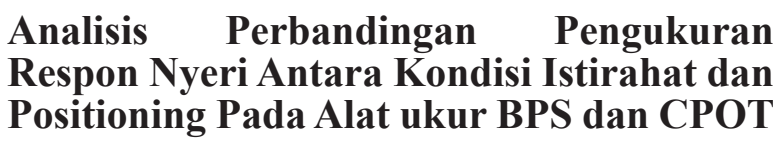

Berdasarkan Tabel 1, dengan menggunakan uji Wilcoxon, terdapat perbedaan respon nyeri antara kondisi positioning dengan respon nyeri dalam kondisi istirahat dengan menggunakan alat ukur BPS dan CPOT. Hal ini menunjukkan bahwa alat ukur CPOT dan BPS keduanya terbukti andal dapat mengukur perbedaan skala nyeri pada kondisi istirahat dan positioning.

\section{Korelasi Pengukuran Nyeri Antara Alat Ukur Nyeri BPS dan CPOT}

Berdasarkan Tabel 2, pada uji korelasi antara BPS istirahat dengan BPS positioning diperoleh nilai $\mathrm{p}<0,05$ yang menunjukkan bahwa korelasi adalah bermakna. Nilai korelasi Spearman sebesar 0,364 menunjukkan bahwa arah korelasi positif dengan kekuatan korelasi rendah. Hal ini menunjukkan bahwa tinggi rendahnya hasil pengukuran BPS dalam kondisi istirahat berkorelasi rendah dengan tinggi rendahnya hasil pengukuran BPS dalam kondisi positioning. Uji korelasi antara CPOT istirahat dengan CPOT positioning diperoleh nilai significancy $\mathrm{p}<0,05$ yang menunjukkan bahwa korelasi adalah bermakna. Nilai korelasi Spearman sebesar 0,323 menunjukkan bahwa arah korelasi positif dengan kekuatan korelasi rendah. Dengan demikian, hal ini menunjukkan bahwa tinggi rendahnya hasil pengukuran CPOT dalam kondisi istirahat berkorelasi rendah dengan tinggi rendahnya hasil pengukuran CPOT dalam kondisi positioning.

Hasil uji korelasi antara BPS istirahat dengan CPOT positioning diperoleh nilai significancy $p>0,05$ yang menunjukkan bahwa korelasi adalah tidak bermakna . Dengan demikian, hal ini menunjukkan bahwa tinggi rendahnya hasil pengukuran BPS dalam kondisi istirahat tidak berkorelasi dengan tinggi rendahnya hasil pengukuran CPOT dalam kondisi positioning. Pada uji korelasi antara BPS Positioning dengan CPOT istirahat diperoleh nilai significancy $\mathrm{p}<0,05$ yang menunjukkan bahwa korelasi adalah bermakna. Nilai korelasi Spearman sebesar 0,419 menunjukkan bahwa arah korelasi positif dengan kekuatan korelasi sedang. Dengan demikian, hal ini menunjukkan bahwa tinggi rendahnya hasil pengukuran CPOT dalam kondisi istirahat berkorelasi sedang dengan tinggi rendahnya hasil pengukuran BPS dalam kondisi positioning.

Berdasarkan pada uji korelasi alat ukur BPS dengan alat ukur CPOT diperoleh nilai $\mathrm{p}=$ 0,000 yang menunjukkan bahwa korelasi hasil pengukuran dengan menggunakan alat ukur BPS dan CPOT adalah bermakna $(p<0,05)$. Nilai korelasi Spearman pada BPS-CPOT pada kondisi istirahat sebesar 0,967 menunjukkan bahwa arah korelasi positif dengan kekuatan korelasi sangat kuat. Nilai korelasi Spearman pada BPS-CPOT pada kondisi positioning sebesar 0,733 menunjukkan bahwa arah korelasi positif dengan kekuatan korelasi kuat. Dengan demikian, hal ini menunjukkan bahwa tinggi rendahnya hasil pengukuran dengan menggunakan alat ukur CPOT

Tabel 2 Analisis Korelasi Pengukuran Nyeri Antara Alat Ukur BPS dan CPOT

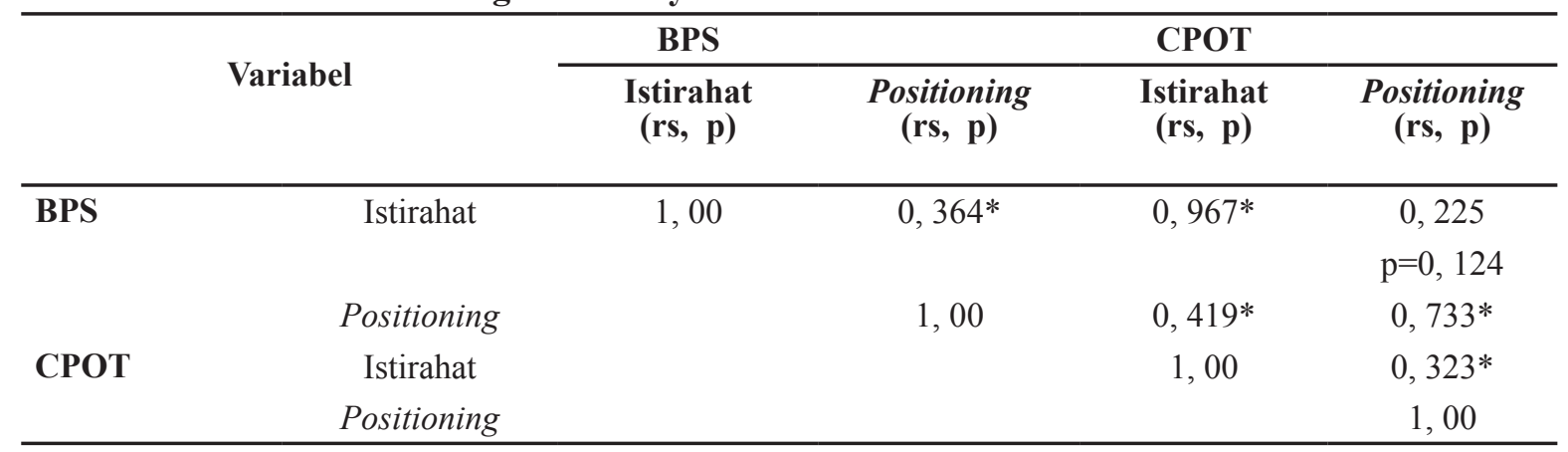

Keterangan: ${ }^{*} \mathrm{p}<0,05$ 
Ayu Prawesti Priambodo: Pengkajian Nyeri Pasien Kritis Menggunakan Critical Pain Observation Tool

Tabel 3 Analisis Kesesuaian Alat Ukur CPOT dan BPS dalam Pengukuran Respon Nyeri pada Kondisi Istirahat (yang telah disesuaikan)

\begin{tabular}{ccccc}
\hline & & \multicolumn{2}{c}{ CPOT Istirahat } & Total \\
\cline { 3 - 5 } & & Tidak Nyeri & Nyeri Ringan & \\
\hline \multirow{3}{*}{ BPS Istirahat } & Tidak Nyeri & 27 & 1 & 28 \\
& & $(57,4 \%)$ & $(2,1 \%)$ & $(59,6 \%)$ \\
& Nyeri Ringan & 0 & 19 & 19 \\
& & $(0 \%)$ & $(40,4 \%)$ & $(40,4 \%)$ \\
\hline \multirow{3}{*}{ Total } & 27 & 20 & 47 \\
& & $(57,4 \%)$ & $(40,4 \%)$ & $(100 \%)$ \\
\hline
\end{tabular}

Keterangan : Kappa Index $=0,956$

$\mathrm{p}=0,000(\mathrm{p}<0,05)$

Tabel 4 Analisis Kesesuaian CPOT dengan BPS pada Kondisi Positioning

\begin{tabular}{cccccc}
\hline & \multicolumn{3}{c}{ CPOT Positioning } & Total \\
\cline { 3 - 5 } & & Nyeri Ringan & Nyeri Sedang & Nyeri Berat & \\
\hline BPS Positioning & Nyeri Ringan & 14 & 17 & 0 & 31 \\
& & $(29,2 \%)$ & $(35,4 \%)$ & $(0,0 \%)$ & $(64,6 \%)$ \\
& Nyeri Sedang & 1 & 12 & 3 & 16 \\
& & $(2,1 \%)$ & $(25 \%)$ & $(6,3 \%)$ & $(33,3 \%)$ \\
& \multirow{6}{*}{ Nyeri Berat } & 0 & 0 & 1 & 1 \\
& $(0,0 \%)$ & $(0,0 \%)$ & $(2,1 \%)$ & $(2,1 \%)$ \\
\hline Total & 15 & 29 & 4 & 48 \\
& $(31,3 \%)$ & $(60,4 \%)$ & $(8,3 \%)$ & $(100 \%)$ \\
\hline
\end{tabular}

Keterangan : Kappa Index 0, $265(\mathrm{p}=$ 0, 011

memiliki korelasi yang sangat kuat dengan tinggi rendahnya hasil pengukuran dengan menggunakan alat ukur BPS pada kondisi yang sama.

\section{Kesesuaian (Agreement) Alat Ukur Nyeri BPS dan CPOT}

Tabel 3 menggambarkan hasil rumus kappa, menunjukkan bahwa kesesuaian hasil pengukuran dengan menggunakan alat ukur CPOT dan BPS adalah bermakna $\quad(p<$ 0 , 05), dengan nilai Kappa sebesar 0, 956 menunjukkan tingkat agreement sangat baik.

Berdasarkan Tabel 4, Dengan menggunakan rumus kappa maka diperoleh besar probabilitas agreement (Po) 29,2\% pada kategori nyeri ringan-nyeri ringan, $25 \%$ pada kategori nyeri sedang-nyeri sedang dan 2,1\% pada kategori nyeri berat-nyeri berat. Nilai probabilitas ketepatan dalam matriks $(\mathrm{Pe})$ sebesar $3 / 9=$ 0,33 . Dengan menggunakan rumus kappa maka diperoleh diperoleh nilai significancy 0,011 yang menunjukkan bahwa kesesuaian antara hasil pengukuran nyeri oleh CPOT dan BPS adalah bermakna $(p<0,05)$, dengan nilai kappa sebesar 0,265 menunjukkan tingkat agreement cukup baik (fair agreement).

\section{Pembahasan}

Hasil penelitian ini menunjukkan bahwa kedua alat ukur nyeri yaitu BPS dan CPOT memiliki keandalan dalam menilai rasa nyeri pada pasien kritis, bagi pasien yang tidak mampu melaporkan rasa nyerinya secara verbal. Hal ini ditunjukkan pada hasil analisis uji beda skor respon nyeri saat istirahat dengan skor respon nyeri saat positioning pada alat ukur BPS dan CPOT adalah bermakna ( $p<0,05)$. Hal ini menjelaskan bahwa kedua alat ukur BPS dan CPOT dapat mengukur perbedaan tingkat respon nyeri 
Ayu Prawesti Priambodo: Pengkajian Nyeri Pasien Kritis Menggunakan Critical Pain Observation Tool

pada saat istirahat dengan respon nyeri saat positioning pada pasien kritis. Pada pasien kritis, rasa nyeri dapat dirasakan, meskipun dalam kondisi istirahat (chanques et al., 2007) ataupun selama tindakan yang menimbulkan rasa nyeri (puntillo et al., 2014) termasuk positioning, sehingga sejumlah indikator perilaku nyeri dapat diamati menggunakan BPS maupun CPOT (Gelinas et al.,2006; Gelinas \& Johnston 2007). Penggunaan BPS (payen et al., 2007) maupun CPOT (Gelinas et al., 2006) pada kondisi ini, merupakan alat ukur yang valid yang direkomendasikan untuk pasien kritis (Herr et al., 2011).

Hasil uji analisis korelasi rank spearman antara hasil pengukuran respon nyeri saat istirahat dengan skor nyeri saat positioning pada masing - masing alat ukur BPS dan CPOT menunjukkan tingkat korelasi yang rendah. Nilai korelasi BPS istirahat-positioning sebesar 0,364 sedangkan nilai korelasi CPOT istirahat-positioning sebesar 0,323 . Hal ini menunjukkan bahwa tingginya tingkat nyeri seseorang pada kondisi istirahat yang diukur menggunakan alat ukur BPS dan CPOT, belum tentu akan menunjukkan tingkatan nyeri yang lebih tinggi pada pengukuran saat positioning, apabila dibandingkan dengan pasien yang memiliki tingkatan nyeri lebih rendah saat pengukuran pada kondisi istirahat. Hal ini terjadi disebabkan karena pasien bersifat individual dalam responnya terhadap nyeri. Rasa nyeri memiliki makna tersendiri pada tiap individu, yang dipengaruhi oleh latar belakang budayanya (Davidhizr et al., 1997; Marrie, 2002).

Hasil uji analisis korelasi pengukuran respon nyeri antara alat ukur BPS dengan CPOT pada kondisi istirahat dan positioning. menunjukkan korelasi yang kuat antara alat ukur CPOT dengan alat ukur BPS ( $\rho$ istirahat $=0,967, \rho$ positioning $=0,733, \mathrm{p}<0,05)$. Hal ini menjelaskan bahwa pada pengukuran respon nyeri pada alat ukur CPOT pada saat istirahat maupun pada saat positioning berkorelasi dengan hasil pengukuran pada pasien yang sama dengan menggunakan alat ukur BPS. Tinggi rendahnya skor nyeri yang diukur oleh CPOT berhubungan dengan tinggi rendahnya hasil ukur menggunakan BPS, sehingga dapat disimpulkan bahwa CPOT memiliki keandalan yang sama dengan BPS dalam mengukur/mengkaji nyeri pada pasien kritis. Hal ini sejalan dengan penelitian Gelinas et al., (2006) yang menyatakan terdapat hubungan yang signifikan antara nilai CPOT dengan laporan diri pasien tentang rasa nyerinya yang dianggap sebagai Gold Standard.

Berdasarkan uji Kappa index menunjukkan bahwa BPS dan CPOT memiliki tingkat kesesuaian (agreement) yang sangat baik (Kappa $=0,937, \mathrm{p}<0,05)$ pada pengukuran yang dilakukan pada saat istirahat, sedangkan tingkat kesesuaian (agreement) BPS dan CPOT pada pengukuran yang dilakukan pada saat positioning memiliki tingkat kesesuaian yang cukup baik (Kappa $=0,265, \mathrm{p}<0,05)$. Hal ini terjadi dapat disebabkan oleh beberapa faktor, diantaranya yaitu BPS memiliki butir observasi yang lebih banyak, yaitu 4 butir pada setiap domain pada alat ukurnya dibandingkan dengan CPOT. Sebagai contoh, pada domain ekspresi wajah, pada BPS terbagi menjadi elemen rileks, sebagian tegang, seluruh bagian tegang dan meringis. Sedangkan pada CPOT, domain ekspresi wajah hanya terbagi menjadi 3 elemen yaitu, rileks, tegang dan meringis. Hal ini menyebabkan BPS lebih banyak menilai respon nyeri pada kategori nyeri ringan, sedangkan CPOT lebih banyak menilai respon nyeri pada kategori nyeri sedang.

Faktor kedua yang dapat menyebabkan rendahnya tingkat kesesuaian antara BPS dan CPOT pada kondisi positioning yaitu, ketidakkonsistenan pada interrater reliability dariBPS, dikarenakanpemahamanyangambigu dari beberapa butir pada tiap indikatornya ( $\mathrm{Li}$ et al., 2008). Hal ini menunjukkan kurangnya definisi operasional pada alat ukur BPS. Berbeda halnya dengan BPS, CPOT memiliki definisi operasional yang lebih jelas, sehingga memudahkan untuk digunakan dalam pengkajian nyeri. Hal ini merupakan salah satu kelebihan alat ukur CPOT). Selain itu, CPOT juga memiliki domain observasi nyeri pada pasien yang mampu memverbalisasikan nyerinya dan pada pasien dengan intubasi. CPOT memiliki kelebihan dalam hal definisi operasional sehingga lebih mudah dipahami dan diaplikasikan kerena CPOT adalah alat yang dikembangkan menggunakan unsurunsur rasa nyeri yang ada pada beberapa alat ukur pengkajian nyeri sebelumnya termasuk BPS, dan aspek-aspek lain berasal dari penulis sebelumnya (Gelinas et al., 2007). 
Ayu Prawesti Priambodo: Pengkajian Nyeri Pasien Kritis Menggunakan Critical Pain Observation Tool

CPOT merupakan alat ukur yang memiliki kesesuaian hasil ukur dengan BPS yang merupakan alat ukur pendahulu untuk rasa nyeri pada pasien kritis, namun CPOT memiliki kelebihan pada penggunaannya yang lebih aplikatif dan mudah untuk dipahami. Hal ini sejalan dengan hasil penelitian Rose et al., 2013 yang menyebutkan bahwa CPOT meningkatkan dokumentasi pengkajian nyeri , dan perawat melaporkan bahwa CPOT membantu mereka melakukan pengkajian nyeri dengan lebih efektif.

\section{Simpulan}

Alat ukur BPS dan CPOT dapat mengukur perbedaan tingkat respon nyeri pada saat istirahat dengan respon nyeri saat positioning pada pasien kritis. Terdapat hubungan antara hasil pengukuran respon nyeri oleh Behavioural Pain Scales (BPS) dengan hasil pengukuran oleh Critical Pain Observation tool (CPOT). Hasil ukur CPOT memiliki tingkat kesesuaian (agreement) yang baik dengan hasil ukur BPS pada pengukuran yang dilakukan pada saat istirahat dan positioning

CPOT merupakan alatukurnyeriyang cukup aplikatif untuk digunakan di area perawatan kritis karena memiliki definisi operasional yang jelas pada setiap butir observasinya. CPOT juga memiliki domain observasi nyeri pada pasien yang mampu melaporkan rasa nyerinya. Penelitian lebih lanjut diperlukan untuk mengetahui pengaruh penggunaan alat ukur pengkajian nyeri terhadap praktik manajemen nyeri dan outcome pada pasien.

\section{Daftar Pustaka}

Ahlers, S., VanGulik, L., Van der veen, Van Dongen, H., Bruins, P., \& Belitser, S. (2008). Comparison of different pain scoring systems in critically ill patients in a general ICU. Critical Care, 12.

Barr, J., Fraser, G.L., Puntillo, K.A., Ely, E.W., Gelinas, C., Dasta, J.F., et al. (2013). Clinical practice guidelines for the management of pain, agitation, and delirium in adult ICU patients. Crit Care Med, 41, 263-306.
Bor-Seng-Shu, E., Paiva, Ws., Figueiredo, Eg., Fujimoto, Y., De Andrade, A., Fonoff, Et., et al. (2013). Post traumatic refractory intra cranial hypertension and brain herniation syndrome. Biomed Res Int.

Chanques, G., Jaber, S., Barbotte, E., Violet, S., Sebbane, M., Perrigault, P., et al. (2006). Impact of systematic evaluation of pain and agitation in an intensive care unit. Crit Care Med, 34, 1691-9.

De Jong, A., Molinari, N., De Lattre, S., Gniadek, C., Carr, J., Conseil, M., et al. (2013). Decreasing severe pain and serious adverse events while moving intensive care unit patients. Crit Care, 17(2), R74.

Futier, E., Chanques, G., Constantin, C., Vernis, L., Barres, A., Guerin, R., et al. (2012). Influence of opioid choice on mechanical ventilation duration and length of stay. Minerva Anestiol, 78(1), 46-53.

Gelinas, C. (2007). Management of pain in cardic surgery ICU patients: Have we improved over time? Intensive Crit Care Nurs, 23, 298-303.

Gelinas, C., Fillion, L., Puntillo, K.A., Viens, C., \& Fortier, M. (2006). Validation of the critical care pain observation tool in adult patients. American Journal of Critical Care, $15,420-427$.

Gelinas, C., \& Johnston, C. (2007). Pain assessment in the critically ill ventilated adult: Validation of the critical care observation tool and physiologic indicators. Clinical Journal of the Pain, 23, 497-505.

Herr, K., Coyne, P., Key, T., Manworren, R., McCaffery, M., \& Merkel, S. (2006). Pain assessment in the nonverbal patient: Position statement with clinical practice recomendations. Pain Management Nursing, 7, 44-52.

Li, D., Puntillo, K.A., \& Miaskowski, C. (2008). A review of objective pain measures for use with critical care adult patients unable to selfreport. The Journal of Pain, 9, 2-10. 
Ayu Prawesti Priambodo: Pengkajian Nyeri Pasien Kritis Menggunakan Critical Pain Observation Tool

Myhren, H., Ekeberg, O., Toien, K., Karlsson, S., \& Stokland, O. (2010). Post traumatic stres, anxiety and depression symptoms in patients during the first year post intensive care unit discharge. Crit Care, 14, R14.

Pasero. (2009). A Assessment of Sedation during Opioid Administration for Pain Management. Journal of Perianastesia Nursing, 186-190

Payen, J.F., Changques, G., Mantz, J., Hercule, C., Auriant, I., Leguillou, J.L., et al. (2007). Current practice in sedation and analgesia for mechanically ventilated criticall ill patients. Anesthesiology, 106, 687-95.

Payen, J.F., Bosson, J.L., Chanques, J., Mantz, J., Labarere, et al. (2009). Pain assessment is associated with decreased duration of mechanical ventilation duration in intensive care unit. Anesthesiology, 111(6), 1308-16.

Puntillo, K.A., Max, A., Timsit, J.F., Vignoud, L., Chanques, G., Robleda, G., et al. (2014). Determinants of procedularal pain intensity in the intensive care unit. Am J Respir Crit Care Med., 189, 39-47.
Rose, L., Smith, O., Gelinas, C., Haslam, L., Dale, C., Luke, E., et al. (2012). Critical care nurses pain assessment and management practices: A survey in Canada. Am J Crit Care, 21(4), 251-9.

Sessler et al. (2008). Evaluating and Monitoring Analgesia and Sedation in the Intensive Care Unit, Crtical Care.12.

Sifflet, J., Young, J., Nikoletti, S., \& Shaw, T. (2007). Patients self report of procedural pain in the intensive care unit. J Clin Nurs, 16(11), 2148-8.

Tahka, S., Axelin, A., Aantaa, R., Lund, V., \& Salantera, S. (2009). Pain assessment tools for unconscious or sedated intensive care patients: A systematic review. Journal of Advanced Nursing, 65, 946-956.

Young J, Siffleet J, Nikoletti S, \& Shaw T. (2006). Use of a behavioural Pain Scale to assess pain in ventilated, unconcious and or sedated patients. Intensive and Critical Care Nursing, 22, 32-39. 